\title{
Discurso e protagonismo: população em situação de rua na produção discursiva de $O$ Trecheiro
}

\section{Discourse and protagonism: homeless \\ population in the discursive production of O Trecheiro}

María del Pilar Tobar Acosta*

Instituto Federal de Brasília

Universidade de Brasília

Brasília, Distrito Federal / Brasil

Viviane de Melo Resende**

Universidade de Brasília

Conselho Nacional de Desenvolvimento Científico e Tecnológico

Brasília, Distrito Federal / Brasil

RESUMO: Neste artigo, que tem por objetivo discutir protagonismo e linguagem, focalizamos entrevistas com o editor do jornal $O$ Trecheiro e um texto publicado no mesmo jornal. Esses dados ilustram questões centrais de acesso discursivo ao debate do protagonismo na linguagem. A posição autoral de textos com acesso a espaços discursivos é um aspecto crucial quando se vinculam protagonismo e linguagem. Por isso, analisar como a posição objetiva de autor/a é ocupada subjetivamente é relevante para compreender o papel de um veículo midiático alternativo na promoção de mudanças na sociedade.

PALAVRAS-CHAVE: protagonismo; acesso; análise de discurso crítica; situação de rua.

ABSTRACT: In this paper, which aims to discuss protagonism and language, we focus on interviews with the editor of the newspaper $O$ Trecheiro and a text published in the same newspaper. These data illustrate issues of discursive access central to the debate of protagonism in language. The authorial position of texts with access to discursive spaces is a crucial aspect when linking protagonism and language. For this reason, analyzing how the objective position of author is subjectively occupied is relevant to understanding the role of an alternative media vehicle in promoting change in society.

KEYWORDS: protagonism; access; critical discourse analysis; homelessness.

\footnotetext{
* acosta.pilar@gmail.com

** resende.v.melo@gmail.com
} 


\section{Introdução}

Em face da brutalidade sistêmica e de todas as pressões que dela advêm, a mobilização social pode ser uma via subversiva para combater, na arena social, incongruências entre o Estado de direito e a violação de direitos sociais. Assim, emergem ações descoladas dos círculos de poder hegemônico, no âmbito da mobilização social: são as organizações não governamentais (ONG) ou organizações da sociedade civil (OSC) voltadas para a luta em favor de grupos socialmente desfavorecidos.

Algumas dessas organizações assumem a prestação de serviços e o exercício do papel que cabe ao Estado, que no quadro do neoliberalismo se encolhe como sustentador do equilíbrio social. Elas buscam promover equilíbrio entre o público e o privado, sendo uma espécie de "tripé" em que assentam Estado, mercado e sociedade. Assim, são classificadas como "terceiro setor", que age "numa interseção entre o espaço público e o privado, reunindo virtudes de ambos para a promoção do bem comum" (OLIVEIRA; HADDAD, 2001, s/p.).

Além desse eixo de atuação, algumas OSC atuam na construção simbólica de outro sistema global, em moldes de cooperação e igualdade entre seres humanos, promovendo, para além da redistribuição de recursos materiais, a equalização do acesso a recursos simbólicos. Essas OSC têm o potencial de serem catalizadoras de mudanças nas práticas sociais, no fortalecimento de atores sociais fragilizados pelo sistema (RESENDE, 2008), e mudanças nas práticas podem, em um segundo momento, promover mudanças profundas na organização estrutural da sociedade.

A Rede Rua é exemplo de mobilização que, por meio de ações materiais e simbólicas combinadas, orienta-se para esse "ethos redistributivo" (SANTOS, 2005, p. 8) e intenta reverter as graves consequências da desigualdade social. Pode-se destacar o veio simbólico que se materializa por meio da publicação de produtos midiáticos voltados para a realidade das ruas e que ocupam uma frente discursiva de ação.

Neste artigo, apresentam-se alguns dos resultados do projeto de pesquisa Protagonismo face à inevitabilidade da violência: vozes da rua em Ocas e em O Trecheiro (ACOSTA, 2012), um dos trabalhos realizados no escopo do projeto integrado "Publicações em língua portuguesa sobre população em situação de rua: análise de discurso crítica" (FAP-DF Processo 193000039/2012). Para esse breve recorte, visando uma discussão sobre protagonismo e linguagem, escolhemos focalizar entrevistas com o editor 
do jornal $O$ Trecheiro e um texto publicado no mesmo jornal. ${ }^{1}$ Esses dados ilustram questões de acesso discursivo que nos parecem centrais ao debate do protagonismo na linguagem. O artigo foi dividido em três seções: na primeira, contextualizamos o jornal em tela e seu escopo de atuação; na segunda, retomamos questões dos estudos críticos do discurso que nos parecem relevantes à relação protagonismo-linguagem; na terceira, apresentamos breve análise discursiva e, em seguida, nossas considerações finais.

\section{Trecheiro: publicação pioneira voltada para a situação de rua}

Para compreender a gênese de $O$ Trecheiro, é necessário revisitar a história dos movimentos sociais que começaram, de maneira embrionária, na década de 1980 na cidade de São Paulo (ROSA, 2005). Sua história está integrada a movimentos ligados a diferentes instituições, como a Organização de Auxílio Fraterno (OAF), que promovia a distribuição de alimentos, em especial de um sopão produzido "por todos e para todos", conforme Alderon Costa, que, quando da realização de nossa pesquisa, era presidente da Rede Rua e editor-chefe do jornal O Trecheiro. Ainda segundo ele, durante as ações de assistência, já em meados de 1980, havia o interesse pela formação política do grupo de pessoas assistidas. Ele conta que:

tinha um grande encontro também que era feito também com essa modalidade da sopa, era feito com, não era feito para, que era "A Missão". Esse encontro era preparado quatro meses, até seis meses antes, toda preparação desde o tema que era escolhido à comida que ia ser distribuída nos dias, e não se aceitava doação. [...] E a gente preparava este encontro, e esse encontro, depois que terminava este encontro saía

\footnotetext{
${ }^{1}$ A pesquisa da qual este artigo é recorte focalizou dois periódicos voltados para a população em situação de rua da cidade de São Paulo: a revista Ocas e o jornal O Trecheiro. Optamos por construir três corpora - o primeiro, de dados documentais de textos publicados na revista Ocas; o segundo, de dados documentais de textos publicados no jornal O Trecheiro; o terceiro, de dados de campo, de entrevistas realizadas com pessoas envolvidas com a produção da revista Ocas e do Jornal O Trecheiro. Os dados de entrevistas foram transcritos para fins de análise discursiva crítica, sem serem considerados aspectos de interação que não estavam no escopo da investigação, tendo em vista que tínhamos como objetivo acessar significados sociais articulados pelos entrevistados na ação discursiva, em especial focalizando a representação da ação. Ao processar os dados para as análises, os corpora documentais foram triangulados pelo corpus de dados de entrevistas, que nos permitiram adensar a análise de conjuntura que apresentamos como forma de delimitação do objeto de investigação.
} 
um relatório desse encontro em forma de notícias, e aí isso foi constante. O Trecheiro acho que ele tem uma origem aí. E a gente estava sempre muito preocupado com esta questão da formação, era um período que a gente achava que tinha que dar consciência para as pessoas, isso era muito forte, a gente tinha que politizar as pessoas, tinha que instrumentalizá-las, empoderá-las mesmo do conteúdo que nós achávamos que era o melhor, isso é um... Hoje a gente olhando eu acho que era um dos equívocos, que não era tão grave, fazia parte daquele contexto, enfim. E aí a gente começou, bom aí fazia esses relatórios, e a gente começou também a preocupar em documentar isso em forma mais sistematizada, aí surgiu o primeiro áudio visual produzido na rua, que foi o do Tatão, chama " $\mathrm{O}$ Minhocão". (Alderon Costa)

Assim, um embrião de $O$ Trecheiro era produzido nesses grandes encontros que reuniam a comunidade articulada na assistência a pessoas em situações de vulnerabilidade, sendo ao mesmo tempo resultado dessa congregação e registro desses eventos. Sobre como eram conduzidos os encontros, com o distanciamento do tempo, Costa observa como a imposição de determinados conceitos não era a ação mais acertada, mas isso revela o caráter político e redistributivo, em termos de bens simbólicos, que está na origem do que viria a ser o jornal $O$ Trecheiro. A essa articulação entre diferentes grupos e movimentos, soma-se:

um ator bem interessante e importante na história do O Trecheiro, que é o Arlindo Pereira Dias. O Arlindo, ele acaba[va] de ser ordenado padre em [19]88, tem [tinha] exatamente 25 anos, ele na verdade é o fundador do jornal, a pessoa que acreditou que era possível fazer um jornal e bancou isso, né? (Alderon Costa)

Foi então que um segundo embrião do que seria $O$ Trecheiro começava a ser produzido, com o nome de Jornal da Rua, como resultado da missão empreendida pelo padre Arlindo Dias, a partir de 1987, junto à comunidade de pessoas em situação de rua da região do Parque Dom Pedro, em São Paulo. A esse respeito, Alderon Costa relatou:

Bom, o Arlindo começa a fazer a documentação dessa missão de uma forma já diferente, já faz uma sulfite mais popular com uma linguagem mais... que as pessoas reconhecem mais, daí ele surge com o Jornal da $\mathrm{R} u a$, depois passa a missão, ele começa a fazer pequenas notícias, e faz uma folha sulfite e chama Jornal da Rua. Esse Jornal da Rua ele chega... ele vai chegar em [19]91, né? [19]91 ainda é o Jornal da Rua, acho. Bom, 
no final de [19]90 ainda está usando esse jornal, ele não tem uma sistematização, assim uma periodicidade, vai soltando conforme vai conseguindo fazer.

A iniciativa foi desenvolvida ao longo da segunda metade dos anos 1990, contando com seis edições. ${ }^{2}$ Em seguida, em meio a um contexto favorável que aliava política e igreja católica, com Luiza Erundina na prefeitura de São Paulo e o cardeal Dom Paulo Evaristo Arns como arcebispo emérito da cidade de São Paulo, o jornal passa a se realizar por meio da articulação de movimentos sociais com a Secretaria Municipal do Bem-Estar Social. A esse respeito, em texto publicado na edição no 200, comemorativa de vinte anos de O Trecheiro, Arlindo Dias conta que: ${ }^{3}$

A ideia de um jornal de rua, de fato, surgiu alguns anos antes de sua materialização. Era parte mais ampla de um projeto de comunicação com, para e a serviço da população de rua. [...] De uma parceria entre poder público e ONG ligada à Igreja Católica nascia o Centro de Documentação e Comunicação dos Marginalizados (CDCM), projeto de comunicação a serviço da população de rua de São Paulo.

Os primeiros dias de trabalho geraram um pequeno folheto batizado com o nome de $O$ Trecheiro. Hoje, mais maduro e com uma fisionomia diferenciada, ele entra em sua fase adulta. É apenas o começo de uma história a ser contada. Parabéns ao O Trecheiro! Há, ainda, muito trecho a percorrer! (DIAS, 2011a, p. 1)

Assim, o jornal passa a ser produzido no âmbito da ação do CDCM. Esse centro foi a alternativa encontrada para poder financiar a produção do jornal, que era o foco do movimento encabeçado por Dias. E foi esse recurso que permitiu mobilizar diferentes atores nos momentos inaugurais do jornal. Em outro texto de Dias, publicado na edição n ${ }^{\circ} 201$ de O Trecheiro, lemos sobre como o jornal foi nomeado:

\footnotetext{
${ }^{2}$ Essas edições, assim como praticamente todo o material produzido pelo Centro de Documentação e Comunicação dos Marginalizados (CDCM) e pela Rede Rua, foram cuidadosamente catalogadas e estão disponíveis para pesquisa na sede da Rede Rua, no Brás, em São Paulo.

${ }^{3}$ Disponível em: <https://goo.gl/aRqsTr>. Acesso em: 27 maio 2017.
} 
Após várias discussões sobre que nome dar ao jornal optou-se pelo modo com que as pessoas de rua denominavam a si mesmas: "sou do Trecho, sou Trecheiro!"

Sem grandes pretensões saía o $\mathrm{n}^{\mathrm{o}} 1$, em papel sulfite, com a manchete "Fala Povo da Rua!" O Formato permaneceria até o no 14 - setembro de 1994 (DIAS, 2011b, p. 1).

Atualmente, $O$ Trecheiro é um jornal mensal/bimestral editado, publicado e distribuído na cidade de São Paulo. Vale dizer também que foi o CDCM que deu lugar à formação da Rede Rua de Comunicação, que hoje conduz diferentes ações no campo simbólico, entre elas a produção do jornal em foco, como constava na versão do site da ONG:

Desde os anos de 1980, a Rede Rua promove comunicação a partir dos excluídos. Documenta e assessora a comunicação de movimentos, entidades e grupos sociais e populares.

Jornal "O Trecheiro": Há 15 anos publica a realidade do povo de rua e registra a história de luta e de esperança do povo excluído.

Produção de Vídeos: Produz vídeos socioeducativos e documentários, acompanhando a organização dos grupos populares.

Fotografia: Registra fatos e manifestações de interesse social, principalmente, da população em situação de rua.

Videoteca: Dispõe de 900 títulos que retratam experiências de inclusão social: organização, formação política, humana e religiosa. ${ }^{4}$

Além das ações centralmente discursivas, figuram também como projetos de assistência da Rede Rua, como se pode ler em seu site:

- Rede Rua de Comunicação: produção do Jornal "O Trecheiro", de vídeos educativos, a montagem de um acervo fotográfico e articulação com outras organizações e movimentos sociais.

${ }^{4}$ Disponível em: <https://goo.gl/8nT11A>. Acesso em: 27 maio 2017. 
Refeitório Comunitário Penaforte Mendes: oferece cerca de 500 refeições (café da manhã, almoço e jantar) para pessoas em situação de rua em parceria com a Prefeitura Municipal de São Paulo e outras entidades que colaboram com o fornecimento de alimentação.

- Centro de Acolhida para Adultos por 16 horas - Pousada da Esperança: Em parceria com a Prefeitura de São Paulo, oferece acolhida para 120 pessoas, acompanhamento social que visa à regularização de documentação, elaboração de projeto de vida e encaminhamentos para a rede socioassistencial.

- Núcleo Santo Dias da Silva: São 80 vagas para a rede de assistência social com o objetivo de dar continuidade ao processo de acolhida e preparar e apoiar os conviventes num processo de empoderamento e de autonomia na busca de saída da rua. ${ }^{5}$

Há complementaridade entre as ações assistenciais (para a redistribuição de recursos materiais e, principalmente, o atendimento a necessidades fundamentais de alimentação e abrigo para pessoas em situação de rua) e as ações simbólicas, realizadas na produção de conteúdos textuais, fotográficos e audiovisuais. Nesse quadro, vale destacar que praticamente todas as pessoas que trabalham para a produção do jornal prestam serviços voluntariamente.

Quanto à estrutura física, podemos dizer que o jornal, composto por quatro páginas em formato standard, apresenta semelhanças com os jornais de grande circulação, no que tange à sua organização, sendo um suporte impresso no qual é possível ler textos que materializam gêneros tradicionais do jornalismo - editorial, colunas, reportagens, entrevistas, entre outros. Esses textos são densamente ilustrados com imagens, principalmente fotografias, feitas por Alderon Costa, de pessoas em situação de rua e de atos das mobilizações que figuram como notícia. Algumas dessas fotos foram laureadas com prêmios, inclusive da International Network of Street Papers (INSP).

O Trecheiro focaliza objetivamente questões relativas à situação de rua que são sua premissa básica, desde os embriões até a sua gênese propriamente dita. Todas as informações e notícias por ele veiculadas orbitam essa temática. É possível encontrar no jornal, por exemplo, estudos sobre o trabalho de pessoas em situação de rua, reproduções editadas de

${ }^{5}$ Disponível em: <http://www.rederua.org.br/quem-somos>. Acesso em: 27 maio 2017. 
cartilhas contra a tuberculose, reflexões sobre a política nacional, entre outros textos abordando os mais diversos assuntos, mas sempre com o foco na rua. Isso faz de $O$ Trecheiro um instrumento de resistência social ainda mais forte na luta pela valorização das pessoas que se encontram em situação de vulnerabilidade social, pela forma como é feito e distribuído. Além disso, quando sabemos que pessoas em situação de rua raramente são incluídas entre o público-alvo de produtos midiáticos (RESENDE; PARDO; NIELSEN, 2017), jornais voltados a esse grupo populacional adquirem ainda mais relevância.

À diferença de outros periódicos destinados à população em situação de rua (que realizam o modelo streetpaper), O Trecheiro não tem como objetivo ser uma ferramenta econômica, tendo em vista que sua distribuição é gratuita. Conforme observa Alderon Costa, mesmo estando catalogado no site da INSP, o jornal não faz parte da rede. Em entrevista cedida para nossa pesquisa, ele esclareceu:

Nós não pertencemos ao INSP, né? É... primeiro porque ele [O Trecheiro] não tá dentro dos critérios... Ah, tem uma discussão, nossos representantes da Ocas [revista também produzida em São Paulo e vendida por pessoas em situação de rua] quando vão, a gente sempre demanda essa discussão lá. Porque um dos critérios do INSP é que seja um produto de venda e que seja uma geração de renda. E o jornal não é. Então, ele não entra nessa categoria de streetpaper, né? Que o INSP tem. Agora, é... É uma referência do INSP, o jornal sempre foi, porque... $\mathrm{Na}$ verdade, nós nunca nos preocupamos em participar de concurso, de alguma coisa assim, mas o pessoal da Ocas, eles são fantásticos nisso, né, a turma da editoria da Ocas, né? Principalmente o Márcio, né? E aí, o pessoal começou: "Ah, Alderon, vamos botar tal matéria? Vamos fazer isso." E eles mesmos preparam tudo e mandam, né? Por isso nós tivemos dois prêmios, né, lá no INSP.

Essa fala do editor-chefe do jornal sugere articulação em rede, importante aspecto de movimentos sociais contemporâneos, conforme Gohn (2003), Castells (2001) e Santos (2013). Essa relação entre os produtos discursivos justifica a pertinência de se associarem análises de textos para a compreensão das práticas de mobilização social e em especial das ações discursivas desses movimentos. Na próxima seção, esse argumento se desenvolve por meio dos pressupostos que orientam a análise de discurso crítica. 


\section{Análise de discurso crítica e protagonismo na linguagem}

Em razão da complexidade do conceito de atividade discursiva, segundo o qual se compreende que esta é parte irredutível da vida social (CHOULIARAKI; FAIRCLOUGH, 1999), a análise de discurso crítica (ADC) requer a utilização de epistemologias de diferentes áreas - tais como ciências sociais críticas e ciências da comunicação, entre outras -, que permitam estudar o sistema semiótico, conforme instanciado em práticas específicas, e mapear as relações entre linguagem e sociedade. Assim, a seara da ADC constitui um campo consolidado interdisciplinarmente.

Esse caráter interdisciplinar vem sendo incrementado em diversas investigações que buscam aproximar ainda mais o campo da linguística discursiva de outras áreas do conhecimento e que, assim, procuram efetivamente romper barreiras que isolam epistemologias em limites rígidos. O avanço dessas aproximações de mais a mais está fazendo da ADC uma transdisciplina, ou seja, um campo de epistemologias híbridas, geradas no contato de saberes de diferentes áreas que não são apenas justapostos, mas operacionalizados.

$\mathrm{Na}$ vertente de origem britânica de $\mathrm{ADC}$, que recebeu notáveis contribuições de vertentes latino-americanas, foi construída, com base nos estudos de Chouliaraki e Fairclough (1999) e de Fairclough (2003), uma aproximação interdisciplinar com o realismo crítico (RC) (BHASKAR, 1989). Como resultado, a ontologia estratificada da realidade social, proposta em $\mathrm{RC}$, tem sido operacionalizada para $\mathrm{O}$ desenvolvimento de teoria do funcionamento social $\mathrm{da}^{6}$ linguagem, esforço que tem sido empreendido por pesquisadoras brasileiras como Ramalho (2007), Barros (2015) e Resende (2009; no prelo).

Para compreender onde se situa nosso objeto de estudo propriamente dito - o discurso ou a atividade discursiva em práticas particulares -, é necessário retomar a opção ontológica selecionada. Essa versão de ADC se aproxima dos trabalhos de Harvey (1992), operacionalizando seu conceito de práticas sociais, e também dos de Bhaskar (1998), adotando o modelo transformacional da atividade social para construir uma ontologia social do discurso (ACOSTA, 2012; RESENDE, no prelo; VIEIRA; RESENDE, 2016). O conceito do primeiro autor nos indica

\footnotetext{
${ }^{6}$ Ver também o dossiê de Barros, Vieira e Resende (2016) "Estudos críticos do discurso e realismo crítico: contribuições e divergências”, publicado na revista Polifonia.
} 
o caráter multifacetado das práticas sociais e permite compreender o funcionamento dos momentos das práticas em sua constituição interna. Uma articulação desse aparato teórico com a formulação dos momentos internos da atividade discursiva - os elementos das ordens do discurso, gêneros, discursos e estilos, segundo Fairclough (2003) -, por sua vez, permite compreender como o momento discursivo funciona em práticas particulares. A contribuição de Bhaskar complementa a formulação de um quadro ontológico para estudos discursivos críticos, propondo um modelo do funcionamento da sociedade. Os níveis de abstração dos elementos desse quadro ontológico (estruturas, práticas sociais, eventos) são operacionalizados para a compreensão dos níveis da linguagem (sistemas semióticos, ordens de discurso, textos).

Em RC, entende-se que a estrutura social fornece recursos para ação, ao mesmo tempo em que a constrange, e o potencial que oferece é aberto às imprevisíveis instanciações que se realizam em eventos concretos. A realização desse potencial em eventos, entretanto, é mediada por entidades organizacionais intermediárias que, como o nome indica, organizam o potencial estruturante e viabilizam sua realização nos diversos campos da atividade humana. A materialização do potencial constitui os eventos sociais realizados, que deixam traços empiricamente observáveis, entre os quais estão os traços discursivos instanciados em eventos: os textos que nos servem de objetos em ADC.

Por meio da análise de amostras discursivas historicamente situadas, pode-se perceber a presença dos componentes das práticas sociais no discurso. As práticas sociais dependem (também) do discurso para serem materializadas em eventos sociais, isto é, para serem concretizadas. Assim, é possível associar o mapeamento ontológico de Bhaskar (1989) ao funcionamento do discurso nas práticas sociais. Nessa perspectiva, o potencial da linguagem é também uma estrutura que oferece recursos e impõe constrangimentos para a ação discursiva. Assim como o potencial social estruturante é mediado por práticas sociais para sua realização em eventos, também o potencial semiótico da linguagem é mediado por entidade organizacional intermediária: as ordens de discurso. As ordens de discurso são, nessa relação, equivalentes às práticas sociais, organizando o vasto potencial semiótico para que este seja realizado por atores sociais, sob a forma de eventos discursivos, nos diversos campos da atividade humana. 
Para Fairclough, recontextualizando Foucault (2012), as ordens de discurso são "as combinações particulares de gêneros, discursos e estilos, que constituem o aspecto discursivo de redes de práticas sociais, a faceta socialmente estruturada da linguagem" (FAIRCLOUGH, 2003, p. 220). Assim, as ordens de discurso são, igualmente às práticas no que se refere à relação entre estruturas sociais e a agência humana, o ponto de conexão entre o sistema semiótico abstrato (mecanismos e estruturas discursivas) e sua realização concreta (textos). Ordens de discurso específicas participam na composição das práticas sociais e, nessa perspectiva, diferentes discursos, sendo diferentes formas de representar o mundo, estão atrelados a práticas sociais particulares - o mesmo se aplica a gêneros e estilos particulares. Essas práticas devem ser analisadas segundo a percepção de que são frutos de processos sociais e que na mesma medida os produzem.

Em razão de sua centralidade como entidades organizacionais intermediárias, e por seus elementos não serem linguísticos, mas sociossemióticos, as ordens de discurso constituem o foco de investigações discursivas críticas, tendo em vista "a natureza constitutiva do discurso", que "constitui o social, como também os objetos e os sujeitos sociais" (FAIRCLOUGH, 2001, p. 81). Essa concepção é complementada pelo entendimento de que os discursos são construídos no espaço da interdiscursividade. Vieira e Resende (2016) observam, sobre a configuração de redes de ordens de discurso, que estas constituem um sistema social, "um potencial semiótico estruturado que possibilita e regula nossas ações discursivas". Assim, é necessário compreender como as ordens discursivas, entendidas como "combinações particulares de gêneros, discursos e estilos" (FAIRCLOUGH, 2003, p. 220), relacionam-se entre si.

Há contingências sociais engendradas no discurso e pelo discurso, e são esses recursos-constrangimentos, organizados em relação a práticas sociais específicas, que constituem a essência das ordens de discurso. Nessa perspectiva, toda prática social articula ordenações discursivas particulares, que viabilizam a atividade discursiva, um de seus momentos. As práticas sociais são dinâmicas, sendo cada vez mais evidente, nas práticas contemporâneas, a aproximação de espaços sociais e a hibridação de práticas. Tendo em vista que há sempre ordens de discurso constitutivas e constituídas dessas/nessas práticas, estas também sofrem modificações por meio de trocas promovidas por imbricação entre as ordens. 
A dinâmica das ordens de discurso pode, então, ser compreendida quando uma determinada prática social se associa a outras, promovendo o hibridismo nessas práticas. A maneira como ordens de discurso se relacionam entre si é, igualmente, um desdobramento da percepção discursiva de Foucault (2012). Uma vez que as práticas sociais são multifacetadas, uma alteração em qualquer dos momentos da prática espraia-se para os demais, afetando-os em maior ou menor medida. Nesse sentido, podemos estabelecer a mesma relação da adaptação dos níveis de abstração da realidade social para compreender como se produz a atividade discursiva. As ordens de discurso na contemporaneidade são cada vez mais híbridas, e esses hibridismos se espraiam para todos os elementos das ordens de discurso postas em contato. Nesse sentido, quando práticas sociais particulares, com suas ordens de discurso também específicas, são postas em hibridação, discursos particulares são modificados pelo contato com outros discursos (na interdiscursividade), gêneros particulares são modificados pelo contato com outros gêneros (na intergenericidade) e estilos particulares são afetados pelo contato com outros estilos, gerando formas alternativas de identificação discursiva.

Desse modo, ao mesmo tempo em que esse potencial organizado pelas práticas constrange a ação dos indivíduos, oferece a possibilidade de mudança. Compreende-se que o poder não se retroalimenta simplesmente, e sim se erige com base nos espólios alcançados em batalhas pela hegemonia; assim, é possível entender como se dá o esforço em todas as instâncias da atividade social, inclusive no plano discursivo, para a manutenção do poder. O esforço dos grupos hegemônicos na mobilização de recursos materiais e simbólicos para subsidiar sua luta só se justifica se entendermos o poder de resistência que atores sociais apresentam. Assim, o protagonismo na linguagem é uma questão central aos estudos crítico-discursivos.

À luz da compreensão da dinâmica das ordens do discurso e do conceito de hegemonia operacionalizado a partir de Gramsci (1978), é possível perceber "jogos de consenso e dissenso que atravessam e condicionam a produção simbólica nos meios de comunicação, interferindo na conformação do imaginário social e nas disputas de sentido e de poder na contemporaneidade" (MORAES, 2010, p. 54). Assim, é possível situar os produtos da mídia tradicional e da mídia alternativa conforme essas oposições, e é aí que lançamos os olhos 
para investigar práticas que envolvem a situação de rua. No entanto, em razão de focalizar produtos midiáticos circunscritos às ordens de discurso das práticas sociais de mobilização e resistência, há que se definir igualmente o que é a contra-hegemonia. Moraes (2010, p. 73) observa que "Gramsci (1999, p. 314-5) situa as ações contra-hegemônicas como 'instrumentos para criar uma nova forma ético-política', cujo alicerce programático é o de denunciar e tentar reverter as condições de marginalização e exclusão". A contra-hegemonia, nesse sentido, necessita da formulação de discursos contraideológicos. E o caráter desse tipo de formação discursiva é o interesse central deste artigo, em uma tentativa de compreender como as ações discursivas da Rede Rua são formuladas como resposta e como proposta. Algumas pistas podem ser levantadas a partir do contraste entre os modos de operação ideológicos (já discutidos em diversas pesquisas sobre o jornalismo tradicional; ver, por exemplo, Molina, 2016; Pardo Abril, 2007; Resende, 2015, 2016) e as estratégias textuais empreendidas por atores sociais ligados às práticas de produção discursiva da Rede Rua em seu jornal O Trecheiro.

\section{4 "Vida no trecho" e "Direto da rua": espaços de protagonismo em $O$ Trecheiro}

A terceira seção deste artigo, destinada à análise de dados, coloca em destaque a participação de pessoas em situações de vulnerabilidade social na produção de textos para o jornal. Na primeira subseção, com base em dados gerados em entrevistas, refletimos sobre o acesso a espaços discursivos no jornal $\mathrm{O}$ Trecheiro. $\mathrm{Na}$ segunda, apresentamos análise estruturada de um texto retirado do jornal e cujo autor encontrava-se em situação de rua. $\mathrm{O}$ objetivo desta seção é, por um lado, discutir as condições de elegibilidade para se preencher a posição autoral no veículo midiático em tela e, por outro, analisar representação e identificação em um exemplar textual que nos permite explorar questões de autoria, entendendo a autoria como uma forma de protagonismo pela linguagem.

\subsection{Acesso a espaços discursivos em $O$ Trecheiro}

Em periódicos alternativos, a importância da autoria dos textos - quem escreve para o jornal e como - é redobrada, pois não há, como em suportes da mídia oligárquica, uma legitimação pelo título ou empresa que o mantém. 
Assim, analisar como a posição objetiva de autor/a, disponível na prática social da produção de textos para periódicos contra-hegemônicos, é ocupada subjetivamente por atores sociais (RESENDE, no prelo), mapeando que tipos de identidades relacionais são articulados, é relevante para compreender o papel do objeto focalizado na promoção de mudanças na sociedade.

Sobre a autoria dos textos, é pertinente aproximar este estudo das contribuições de van Dijk (1991), que explorou amplamente a análise dos padrões de acesso a espaços discursivos. Para o autor, é crucial para estudos em ADC investigar como se dá a negociação dos espaços midiáticos, entendendo que:

Um elemento crucial na reprodução discursiva do poder e da dominação é o acesso ao discurso e a eventos comunicativos. A esse respeito, discurso é semelhante a outros recursos sociais valiosos que fundamentam a base do poder e aos quais há uma distribuição desigual do acesso. Nesse sentido, nem todos/as têm igual acesso à mídia ou a textos e falas médicas, legais, políticas, burocráticas ou acadêmicas. (VAN DIJK, 1991, p. 85-86)

Van Dijk aponta alguns critérios para analisar o acesso a eventos discursivos, com base nas questões "quem pode falar ou escrever para quem, sobre o que, quando e em que contexto?" e "quem pode participar em determinados eventos comunicativos e ocupando que papéis?" (VAN DIJK, 1991, p. 86). Por meio da combinação dessa perspectiva teórica com o conceito de sistema posição-prática, do realismo crítico, é possível delimitar condições de elegibilidade para que atores sociais ocupem a posição de produtores/as de texto nas práticas de produção das publicações de $O$ Trecheiro, e ponderar se há uma garantia de acesso a espaços discursivos a pessoas em situação de rua.

Conforme mapeamento feito por Acosta (2012), para ser autor/a de um texto, e assim preencher espaços discursivos abertos em O Trecheiro, é necessário, a todos/as os atores, independentemente da posição que ocupem em outras práticas, ter um grau de letramento relativamente elevado (uma exceção é apresentada a seguir) e estar alinhado com a causa de pessoas em situações de vulnerabilidade. Essas são as duas condições básicas de elegibilidade, mas há outras que variam conforme a posição ocupada pelos atores sociais em outras práticas:

(i) estar inserido/a em movimento social e/ou ter aí posto de liderança; e/ou

(ii) destacar-se como livre pensador/a; e/ou 
(iii) ter se destacado por sua atividade artística; e/ou

(iv) ser leitor/a do jornal e escrever missivas relatando um pouco de sua biografia ou refletindo sobre algum aspecto relevante para a publicação.

Nesse quarto caso, as cartas são publicadas, principalmente, no espaço da seção "Vida no Trecho", em que não há a necessidade desse alto grau de letramento mencionado antes, bem como não há o imperativo de se ocupar qualquer posição mais institucionalizada. Em alguns casos, as missivas em resposta à ação de $O$ Trecheiro são reproduzidas conforme o original nas edições do jornal. Nesses casos, por vezes, a foto do texto manuscrito aparece como imagem ilustrativa ao lado da transcrição (imagem de manuscrito em folha de caderno, por exemplo), o que amplia o caráter de autenticidade e fidelidade com o que foi efetivamente produzido por um ator social que se encontra em situação vulnerável.

Em uma entrevista conjunta com membros da equipe editorial de $O$ Trecheiro foram gerados dados que possibilitaram a compreensão de como se constrói a relação dos/as editores/as com as pessoas em situação de rua e como se dão as negociações para o acesso à posição de autoria. Na entrevista, Costa observou que:

(1) Duas discussões que a gente sempre teve também, que é a participação da população de rua. Como é que essa população pode participar no jornal, né? Aí, vêm todos aqueles textos que a Cleisa já colocou no almoço, a dificuldade que às vezes as pessoas têm de se expressar na escrita. No "Vida no Trecho", a gente resolveu tentando dar prioridade sempre à fala direta dele. Tanto que a orientação que a gente dá pra todo mundo é gravar a vida no trecho. Eu, pessoalmente, eu e a Cleisa, a gente faz só gravar. Porque, aí, você consegue anotar a expressão mesmo que a pessoa fala, né? Eu ouço e eu construo uma frase que pode ter o mesmo sentido, mas não é aquilo que ele falou. Então, o gravador ajuda nisso. Então a gente tentou se aproximar mais da fala dele, a partir dessa metodologia, né? Usando o gravador, esse instrumental. É... O "Direto da Rua", né, ele veio, a tentativa do "Direto da Rua" é responder a isso, né? A essa participação direta da população de rua.

No excerto (1), o então editor chefe de O Trecheiro e presidente da Rede Rua observa que há dificuldades em relação ao baixo grau de letramento de alguns colaboradores e colaboradoras. A esse respeito, em conversa informal, que foi registrada em notas de campo, os/as editores/as de O Trecheiro 
relataram como se dava o procedimento de revisão dos textos veiculados no jornal. Sobre isso, há uma distinção básica no espaço "Vida no Trecho", onde mesmo quando o texto é fruto da transcrição de falas de entrevistas que os/as editores/as realizam com pessoas em situação de rua, há grande preocupação em respeitar o estilo individual de cada colaborador/a.

O que vale ressaltar é o interesse da edição de $O$ Trecheiro em viabilizar o acesso "direto" de pessoas em situação de rua ao espaço discursivo, além do alto grau de reflexividade na busca de soluções para os entraves que se impõem a essa prática, como se nota na "recomendação de gravar" as entrevistas do "Vida no Trecho". Por exemplo, em "Eu ouço e eu construo uma frase, que pode ter o mesmo sentido, mas não é aquilo que ele falou" (trecho da entrevista), podemos analisar a representação da ação de produção do jornal e, mais especificamente, da ação discursiva da produção dos textos para o jornal.

Existe uma diferença marcada entre o ato de "ouvir" e o ato de "construir uma frase": o editor observa que o sentido pode manter-se, mas que se perde "aquilo que foi dito". Nesse sentido, a transcrição do dizer preserva os traços de estilo dos colaboradores e colaboradoras que relatam um pouco de suas vidas para a seção "Vida no Trecho" e, dessa maneira, os significados identificacionais expressos originalmente são mantidos no produto final. Esse cuidado com a produção discursiva marca a ação da publicação e assegura uma coerência com o objetivo final de mudança social, pois muda a perspectiva com que geralmente são tratadas as subjetividades de pessoas desprivilegiadas em termos de poder simbólico, e das fontes jornalísticas de um modo mais geral.

Já nos demais espaços, inclusive na seção "Direto da Rua”, o procedimento de revisão é semelhante ao de jornais tradicionais, havendo a adequação à norma-padrão e a supressão de termos de teor inadequado, tais como "pano de bunda" que, segundo relato, foi uma expressão suprimida de texto de um colaborador que estava em situação de rua, por ter sido compreendida, na revisão, como não essencial para transmitir o que o autor gostaria de expressar e por "pesar" no texto. Assim, todos os textos passam pelo escrutínio editorial do jornal, havendo uma espécie de manual para padronizar todos os textos. Esse processo de revisão e adequação à ação discursiva macro é semelhante às rotinas de produção de periódicos de grande circulação (PEREIRA; ADGHIRNI, 2011). ${ }^{7}$

${ }^{7}$ Em comparação, veja-se o estudo de Santos (2013) sobre o street paper Boca de Rua, de 


\section{2 $O$ exemplo de um texto de $O$ Trecheiro}

Nesta subseção, apresenta-se um brevíssimo recorte de análise discursiva de texto publicado em $O$ Trecheiro na edição de março de 2009. O autor, Daniel Lopes, não é vinculado ao jornal $O$ Trecheiro e também não se vincula a movimentos sociais ou movimentos artísticos, sendo um ator menos institucionalizado nos termos que discutimos na primeira parte desta seção do artigo. Trata-se de "carta de um leitor", que foi publicada com esse título no espaço destinado à seção "Vida no Trecho". Como vimos na fala de Alderon Costa reproduzida antes no excerto (1), trata-se de espaço de resistência, onde há liberdade para a expressão da voz de pessoas em situação de rua.

Para esta análise, consideramos o texto integral e focalizamos as maneiras como estão articulados o identificar(-se) e o representar(-se). A carta constitui-se como um momento de autorreflexão do autor, Daniel Lopes. Vejamos o excerto (2), que reproduz os três primeiros parágrafos do texto: ${ }^{8}$

(2) Eu, Daniel Lopes, hoje com trinta e sete anos, não sou muito bem organizado para o atual estágio da humanidade, ao contrário sou um pouco desestruturado. Você entende, não é, leitor?

Hoje estou desesperado na situação em que me encontro surpreendido em todos os sentidos. Convivo com saúde comprometida, o soro positivo HIV, mas tenho acompanhamento de infectologistas. Menos mau, não é? Graças ao meu bom Deus!

Não dominei conquistas necessárias e importantes para os conteúdos da vida à altura da sobrevivência com dignidade em questão, percebe? Desempregado em situação de rua, com saúde comprometida, aí vem a conclusão mais difícil: a situação financeira atual incompatível ao nível de uma sobrevivência digna na Pauliceia.

$\mathrm{Na}$ abertura da carta, Lopes nos explica quem é, construindo sua identidade por meio de avaliações negativas, quando se trata de sua autoimagem (mas positivas, veremos no excerto (3), quando se refere ao jornal e à possibilidade de escrever um texto para $O$ Trecheiro). Há

Porto Alegre, e suas práticas de produção coletiva de textos.

${ }^{8}$ Disponível em: <http://www.rederua.org.br/o-trecheiro>. Acesso em: 27 maio 2017. 
recorrência de estruturas negativas nas instâncias de autoidentificação, que modalizam com intensidade a avaliação por meio da qual o autor constrói sua autorrepresentação: pelo advérbio "não" - em "não sou muito bem organizado" e em "não dominei conquistas" - e pelo prefixo "des-" - em "desestruturado", "desesperado", "desempregado". Esses marcadores negativos, contudo, são mitigados, nos termos de Pardo (2011), em "não [...] muito bem", em que a intensidade da negação pelo advérbio é restringida pela locução adverbial, e em "ao contrário [...] um pouco", em que a modalização também diminui a intensidade de "desestruturado". Ainda assim, estamos no campo da avaliação negativa.

Essa avaliação é pautada pela (e ao mesmo tempo pauta a) articulação do discurso da competência. Expressa a assimilação do discurso que lhe imputa a responsabilidade por suas condições de vida. Segundo sua autorreflexão, por não ser "organizado", ser "um pouco desestruturado" (sem estrutura), hoje está "desesperado" (sem esperança) e "desempregado" (sem emprego) - uma identificação baseada na ausência, na carência do que se valoriza positivamente. Com base nesse discurso, há a reiteração da identidade legitimadora segundo a qual quem não ocupa um lugar "[n] o atual estágio da humanidade" é responsável por isso. Assim se delineia a representação da culpa por sua condição, o que se ratifica em "Não dominei conquistas necessárias e importantes". O discurso da (não) competência é por fim sintetizado pela expressão taxativa "Desempregado em situação de rua”, que o afasta ainda mais da possibilidade do domínio e da conquista, que avalia por oposição como sendo importantes.

O processo desencadeado por "dominar" objetiva "conquistar" algo, que é "necessário e importante". Por um lado, esse processo instancia uma metáfora conceitual bélica, em razão do léxico empregado. Por outro, novamente, articula um discurso hegemônico em que o consenso é demarcado pelo esvaziamento do referente do que é "necessário e importante", tendo em vista que não se sabe de que "conquistas" ele trata, apenas se sabe que são "conquistas necessárias e importantes". Esse silêncio relativo pode ser descrito como a reprodução do fetichismo capitalista, pelo qual o ter se sobrepõe ao ser, e não importa o que é o ter, havendo o consenso de que esse ter é imprescindível.

Outro aspecto desse excerto que deve ser pontuado é que, mesmo em face dessa pressão discursiva, ele formula um esboço da demanda, expresso pelo desejo de uma "sobrevivência com dignidade", que é reforçado pela hiperlexicalização. Ainda assim, trata-se de um esboço, pois a ideia que 
estaria contida em "vida digna", que é o que todos/as almejam, perde a força em "sobrevivência". A dignidade por que Lopes anseia acaba sendo limitada, e a identificação legitimadora, que sustenta o estado de coisas, novamente é reificada.

Apesar disso, é possível tangenciar uma projeção identitária alternativa por meio de estruturas discursivas que apontam para um questionamento dessa "realidade". Em "estou desesperado", "me encontro surpreendido" e "em situação de rua", Lopes - por meio dos processos explicitados, nos dois primeiros casos pelos verbos estar e encontrar-se, e o implícito "estar", no terceiro - articula em seu texto o discurso contra-hegemônico da transitoriedade da situação de rua, que, por ser "situação", é delineada como fruto de um processo e, por isso, passível de ser superada. Esse mesmo discurso contra-hegemônico é reiterado pela repetição de "situação", termo empregado três vezes no excerto.

Além de elaborar uma construção identitária que oscila entre a legitimação de suas condições e o esboço de um projeto, Daniel Lopes também representa o evento social da escrita. Nessa recontextualização, Lopes representa a si mesmo como produtor do texto e projeta um "leitor": "Você entende, não é, leitor?", "Menos mau, não é?” e "percebe?”. Seu texto se dobra sobre si mesmo: o autor do texto evidencia os momentos de sua composição ao representar o ato de escrever. Esse ato é um tipo de ação social que exige do participante recursos simbólicos inicialmente relacionados ao seu grau de letramento e, sendo um escrever para outro, exige um espaço discursivo em que esse outro possa acessá-lo.

Novamente podemos nos apoiar sobre o conceito de acesso aos espaços discursivos de van Djik (1991), mas em uma via dupla de acesso: o acesso do autor à posição de produtor de texto publicado na mídia e o de leitores/as que podem, pela mediação do jornal, acessar determinados conteúdos simbólicos. Assim, o acesso de Lopes ao jornal nos dá acesso a sua forma particular de representar o mundo e tem o potencial de ampliar o conhecimento sobre a situação de rua e sobre as pessoas que se encontram nessa situação. Nesse sentido, é possível entrever como a ação discursiva macro enseja outras ações discursivas que dificilmente seriam possíveis nos espaços discursivos tradicionais da mídia.

Vejamos o excerto referente à entrevista realizada com Alderon Costa: 
(3) Sempre que sai uma nova edição do mais realista jornal O Trecheiro, o incrível jornal em todas as temporadas, sempre informando e trazendo opções em solidariedade e emoções, espiritualizados com bom saber.

Decidi me debruçar sobre a pilastra do posto onde me abriguei hoje e escrever caligrafando parte de minha vida com prazer dedicado a todos da equipe e direção do meu querido ilustrativo jornal $O$ Trecheiro da Rede Rua, o no. 1 em todos os sentidos.

Essa abertura do espaço discursivo é avaliada de maneira positiva pelo autor do texto, em oposição à maneira como ele se autoavalia. A avaliação feita pelo autor sobre o jornal é extremamente positiva e envolve grande afetividade, como é possível depreender a partir de "emoções", "prazer", "meu querido", "o mais realista", "o incrível", "querido ilustrativo" e "o no. 1". O conteúdo do jornal também é avaliado, sendo ressaltado o caráter qualitativo e perene da produção - "todas", "sempre", "todos". Essa alta intensidade positiva da avaliação do autor - que é leitor do jornal - sobre o veículo, marca um contraste com os primeiros traços analisados, mas abre espaço para uma construção identitária positiva do autor como produtor do texto.

A partir de "Decidi", o espaço da possibilidade (frente à impossibilidade inicial) é construído pela volição. Esse espaço também é construído em "opções" que são oferecidas pelo jornal, que concernem inicialmente à possibilidade de ler assuntos relativos à situação de rua sob um prisma alternativo, mas também podem ser estendidas para a "opção" de escrever. O ato da produção textual é, assim, representado pela descrição de um momento de prazer.

Esse escrever, no entanto, é qualificado como "escrever caligrafando". A expressão aqui é menos direta, e podemos nos perguntar se o autor nesse trecho avalia-se, se avalia seu letramento e seu produto textual, se "caligrafando" diminui a importância do ato da escrita. Ainda que (talvez) seja assim, a novidade de ocupar uma posição de produtor de texto incrementa a identidade desse ator social, é por meio dela que ele evidencia que mesmo em circunstâncias dramáticas de vida, resiste e encontra ressonância para suas demandas.

Nesse sentido, o ato de escrever representado engendra um ler, a ser realizado por uma terceira pessoa. A ideia do/a leitor/a solidário/a aqui se projeta para o texto solidário, no sentido de que o jornal fornece "opções em solidariedade”. A relação com esse/a leitor/a é construída pelo produtor 
de texto por meio das várias perguntas retóricas que formula. Ao cabo, esse leitor ou leitora genérico é delimitado na representação das figuras recontextualizadas da "direção e equipe" a quem o autor dedica o texto. Assim, outro título seria possível: "Carta aos leitores". Essa carta aos/às leitores/as, no final das contas, é o fulcro de todas as ações discursivas, no sentido de que são orientadas para a ampliação do diálogo entre pessoas em situação de rua e a sociedade.

\section{Considerações finais}

Acreditamos que a posição autoral de textos com acesso a espaços discursivos é um aspecto central quando se vinculam protagonismo e linguagem. Por isso, analisar como a posição objetiva de autor/a é ocupada subjetivamente (RESENDE, no prelo) é relevante para se compreender o papel de um veículo midiático alternativo na promoção de mudanças na sociedade. Acosta (2012) realizou um mapeamento das condições de elegibilidade para o papel autoral no jornal O Trecheiro, e entre as condições gerais que elencou selecionamos um texto assinado por um autor menos vinculado institucionalmente, ou seja, um produtor textual que não se vincula diretamente à produção jornalística alternativa, nem à produção artística, nem a movimentos sociais. Analisamos seu texto considerando como pontos focais a identificação e a representação, a fim de compreender como esse autor se identifica na posição autoral e em suas relações com o veículo, e como se apropria do espaço discursivo para representar a situação de rua e a ação do jornal.

\section{Agradecimentos}

Agradecemos à Fundação de Apoio à Pesquisa do Distrito Federal o fomento à realização deste projeto; ao Conselho Nacional de Desenvolvimento Científico e Tecnológico, a bolsa de estudo concedida; aos membros do grupo de pesquisa, Andreia Alves dos Santos e Gersiney Pablo Santos, o trabalho compartilhado; aos membros do Núcleo de Estudos de Linguagem e Sociedade da Universidade de Brasília (NELiS/UnB) e da Rede Latino-Americana de Análise de Discurso Crítica sobre Pobreza (REDLAD), os produtivos ambientes acadêmicos em torno dos quais este projeto se desenvolveu; ao Programa de Pós-Graduação em Linguística da UnB, o suporte institucional. 


\section{Referências}

ACOSTA, M. P. T. Protagonismo face à inevitabilidade da violência: vozes da rua em Ocas e em O Trecheiro. 2012. Dissertação (Mestrado em Linguística) - Universidade de Brasília, Brasília, 2012.

BARROS, S. M. Realismo crítico e emancipação humana: contribuições ontológicas e epistemológicas para os estudos críticos do discurso. Campinas: Pontes, 2015.

BARROS, S. M.; RESENDE, V. M. Estudos críticos do discurso e realismo crítico: contribuições e divergências. Polifonia, Cuiabá, v. 23, n. 33, p. 8-9, 2016.

BHASKAR, R. The possibility of naturalism: a philosophical critique of the contemporary human sciences. Hemel Hempstead: Harvester Wheatsheaf, 1989.

BHASKAR, R. Philosophy and scientific realism. In: ARCHER, M. et al. (Ed.). Critical realism: essential readings. London: Routledge, 1998. p. 16-47.

CASTELLS, M. O poder da identidade. Tradução de Klauss Brandini Gerhardt. 2. ed. São Paulo: Paz e Terra, 2001.

CHOULIARAKI, L.; FAIRCLOUGH, N. Discourse in late modernity: rethinking critical discourse analysis. Edinburgh: Edinburgh University Press, 1999.

DIAS, A. De trecho em trecho: o período de gestação de O Trecheiro. $O$ Trecheiro, v. 20, n. 200, p. 1, 2011 a.

DIAS, A. De trecho em trecho (2): uma folha em branco e preto com muitos ideais e compromissos. O Trecheiro, v. 20, n. 201, p. 1, 2011 b.

FAIRCLOUGH, N. Discurso e mudança social. Brasília: UnB, 2001.

FAIRCLOUGH, N. Analysing discourse: textual analysis for social research. London: Routledge, 2003.

FOUCAULT, M. A ordem do discurso: aula inaugural no Collège de France, pronunciada em 2 de dezembro de 1970. São Paulo: Loyola, 2012.

GOHN, M. G. Movimentos sociais no início do século XXI: antigos e novos atores sociais. Petrópolis: Vozes, 2003.

GRAMSCI, A. Concepção dialética da história. Rio de Janeiro: Civilização Brasileira, 1978.

HARVEY, D. Condição pós-moderna. Tradução de Adail U. Sobral e Maria S. Gonçalves. São Paulo: Loyola, 1992.

MOLINA, L. De la situación de calle a la ocupación del espacio público: representaciones discursivas de las personas en situación de pobreza en los diarios argentinos. In: Colóquio Internacional Da REDLAD, 11., 2016, Brasília. Rede Latino-Americana de Análise de Discurso Crítica sobre a Pobreza. Brasília: UnB, 2016. 
MORAES, D. Comunicação, hegemonia e contra-hegemonia: a contribuição teórica de Gramsci. Revista Debates, Porto Alegre, v. 4, n. 1, p. 54-77, 2010.

OLIVEIRA, A. C.; Haddad, S. Print version As organizações da sociedade civil e as ONGs de educação. Cadernos de Pesquisa. N.112, São Paulo, Mar. 2001. (s/p.) Disponível em: <http://www.scielo.br/scielo.php?script=sci_ arttext\&pid=S0100-15742001000100003 > . Acesso em: 7 ago. 2016.

PARDO ABRIL, N. G. ¿Qué nos dicen? ¿Qué vemos? ¿Qué es pobreza? Análisis crítico de los medios. Bogotá: Universidad Nacional de Colombia, 2007.

PARDO, M. L. Teoría y metodología de la investigación lingüística: método sincrónicodiacrónico de análisis linguístico de textos. Buenos Aires: Tersites, 2011.

PEREIRA, F. H.; ADGHIRNI, Z. L. O jornalismo em tempo de mudanças estruturais. Intexto, Porto Alegre, v. 1, n. 24, p. 38-57, 2011.

RAMALHO, V. C. V. S. Diálogos teórico-metodológicos: Análise de Discurso Crítica e Realismo Crítico. Cadernos de Linguagem e Sociedade, Brasília, v. 8, p. 78-104, 2007.

RESENDE, V. M. Análise de discurso crítica e etnografia: o movimento nacional de meninos e meninas de rua, sua crise e o protagonismo juvenil. 2008. Tese (Doutorado em Linguística) - Universidade de Brasília, Brasília, 2008.

RESENDE, V. M. Análise de discurso crítica e realismo crítico. Campinas: Pontes, 2009.

RESENDE, V. M. A violação de direitos da população em situação de rua e a violência simbólica: representação discursiva no jornalismo on-line. Revista Latinoamericana de Estudios del Discurso, Caracas, v. 15, p. 71-92, 2015.

RESENDE, V. M. Representação de pessoas em situação de rua no jornalismo on-line: quais são as vozes convocadas para falar sobre a situação de rua? Revista de Estudos da Linguagem, Belo Horizonte, v. 26, n. 3, p. 955-88, 2016.

RESENDE, V. M. Análise de discurso crítica: reflexões teóricas e epistemológicas quase excessivas de uma analista obstinada. In: RESENDE, M. V. (Org.). Outras perspectivas em análise de discurso crítica. Campinas: Pontes. No prelo.

RESENDE, V. M.; PARDO, M. L.; NIELSEN, G. Pobreza e jornalismo: práticas transformadoras? Introdução. About Journalism/ Sur le Journalisme, Bruxelles, v. 6, n. 1, p. 4-11, 2017.

ROSA, C. M. Vidas de rua. São Paulo: Hucitec, 2005.

SANTOS, A. A. O jornal =Boca de Rua = espaço de possibilidades para pessoas em situação de rua: uma reflexão discursiva crítica. 2013. Dissertação (Mestrado em Linguística) - Universidade de Brasília, Brasília, 2013. 
SANTOS, B. de S. A crítica da governação neoliberal: O Fórum Social Mundial como política e legalidade cosmopolita subaltern. Revista Crítica de Ciências Sociais. N. 72, p. 7-44, Out. 2005.

VAN DIJK, T. A. Discourse, power and access. In: CALDAS-COULTHARD, C. R.; COULTHARD, M. (Org.). Texts and practices: readings in critical discourse analysis. London: Routledge, 1991. p. 85-104.

VIEIRA, V. C.; RESENDE, V. M. Análise de discurso (para) a crítica. 2. ed. Campinas: Pontes, 2016.

Data de submissão: 23/01/2017. Data de aprovação: 24/05/2017. 